\title{
Tool wear evaluation based on vibration analysis during milling of MMC using diamond coated end mills
}

\author{
MARTYNA WICIAK-PIKUŁA \\ PAWEL TWARDOWSKI \\ AGATA FELUSIAK \\ SZYMON ORŁOWSKI *
}

\author{
Mgr inż. Martyna Wiciak-Pikuła, martyna.r.wiciak@doctorate.put.poznan.pl, https://orcid.org/0000-0003-2648-7091 - Politechnika Po- \\ znańska, Poznań, Polska \\ Dr hab. inż. Paweł Twardowski, prof. nadzw. PP, pawel.twardowski@put.poznan.pl, https://orcid.org/0000-0002-1823-6279 - Politech- \\ nika Poznańska, Poznań, Polska \\ Mgr inż. Agata Felusiak, agata.z.felusiak@doctorate.put.poznan.pl, https://orcid.org/0000-0002-4927-4120 - Politechnika Poznańska, Po- \\ znań, Polska \\ Mgr inż. Szymon Orłowski - ITA spółka z ograniczoną odpowiedzialnością sp.k., Skórzewo, Polska
}

The aim of the research was to analyze the wear of the end mills based on the measurement of mechanical vibration accelerations. The $V B_{\mathrm{B}}$ index was used as the tool wear criterion, which was measured until a specific maximum wear was obtained. The paper compares the tool wear values at different cutting speeds and determines the possibility of predicting the state of the tool wear based on the measurements of mechanical vibration accelerations.

KEYWORDS: metal matrix composite, tool wear monitoring, mechanical vibrations analysis

\section{Introduction}

Metal-ceramic composites (metal matrix composites, MMC) are construction materials, the matrix of which is usually a soft and ductile casting alloy or aluminum alloy for plastic forming, while the reinforcement has the form of hard and brittle ceramic particles. Due to their structure, such composites belong to the group of hardto-machine materials, and due to their mechanical properties, they are used in the aviation, shipbuilding and automotive industries. The largest advantages of these materials are especially high strength and stiffness, which largely depend on the type of strengthening and the content of hard particles [1-4].

High resistance to abrasive wear, resulting from the reinforcement in MMC composites, is associated with difficult machining of these materials. It is necessary to choose the right tool material, because the presence of hard particles in composites leads to accelerated wear of milling tools. In addition, it is necessary to determine the appropriate machining parameters (cutting speed, feedrate, cutting depth), which will extend the tool life $[5,6]$.

When machining metal-ceramic composites, abrasive and adhesive wear is most often noticeable, due to the penetration of hard ceramic particles into the cutting edge material. The tool wear may result in sticking of hard particles on the cutting edge of the tool or picking up of tool material particles and formation of grooves [6]. In materials with ceramic particles PMMCs (particulate metal matrix composites), a build-up is formed, which is a protective barrier for the leading edge of the cutting edge. One example is work [7], in which the formation of build-up during milling of aluminum composite with boron carbide $\mathrm{B}_{4} \mathrm{C}$ inclusions is presented. The appearance of build-up on the cutting edge largely depends on the cutting speed, which is due to the increase in temperature in the cutting zone as a result of the appearance of friction forces between the workpiece and the tool. The lower the cutting speed, the lower the temperature in the cutting zone, and removing the build-up in such conditions becomes more difficult.

Nowadays, a lot of work is focused on monitoring the wear of milling tools made of various tool materials, based on indirect measurements, i.e. measuring the cutting forces, mechanical vibrations or acoustic emissions, 
or on the basis of chip morphology [8-10]. Assessment of sizes that correlate with tool wear is important, because it allows for the tool change before catastrophic failure occurs. This is extremely important when machining difficult-to-cut materials, since the tool life is much lower compared to other construction materials.

The purpose of the research was to analyze the state of the diamond-coated end mills based on the measurement of vibration during milling of metal-ceramic composite with different cutting speeds: 500, 700 and $900 \mathrm{~m} / \mathrm{min}$.

\section{Research scope and methodology}

A popular aluminum-ceramic alloy with SiC silicon carbide inclusions with a content of about $10 \%$ was selected for the research. Side and face milling was performed using monolithic milling cutters with a diamond coating, applied by the CVD method. End mills with three cutting edges with a diameter of $10 \mathrm{~mm}$ were selected.

Variable parameter during the tests was cutting speed $v_{c}: 500,700$ and $900 \mathrm{~m} / \mathrm{min}$. Other parameters were constant: cutting depth $a_{\mathrm{p}}=8 \mathrm{~mm}$, cutting width $a_{\mathrm{e}}=0.3 \mathrm{~mm}$, feedrate per tooth $f_{\mathrm{z}}=0.05 \mathrm{~mm} /$ tooth.

During milling, vibration accelerations were measured with a piezoelectric vibration acceleration sensor for subsequent cutting edge condition analysis. Vibration acceleration was measured in three directions:

- along the $X$ axis - a component consistent with the feed direction $A_{\mathrm{f}}$,

- along the $Y$ axis - main direction $A_{\mathrm{fN}}$,

- along the $Z$ axis - along the direction of the radial force $A_{\mathrm{p}}$.

Diagram of the measuring path used during the tests is shown in fig. 1.

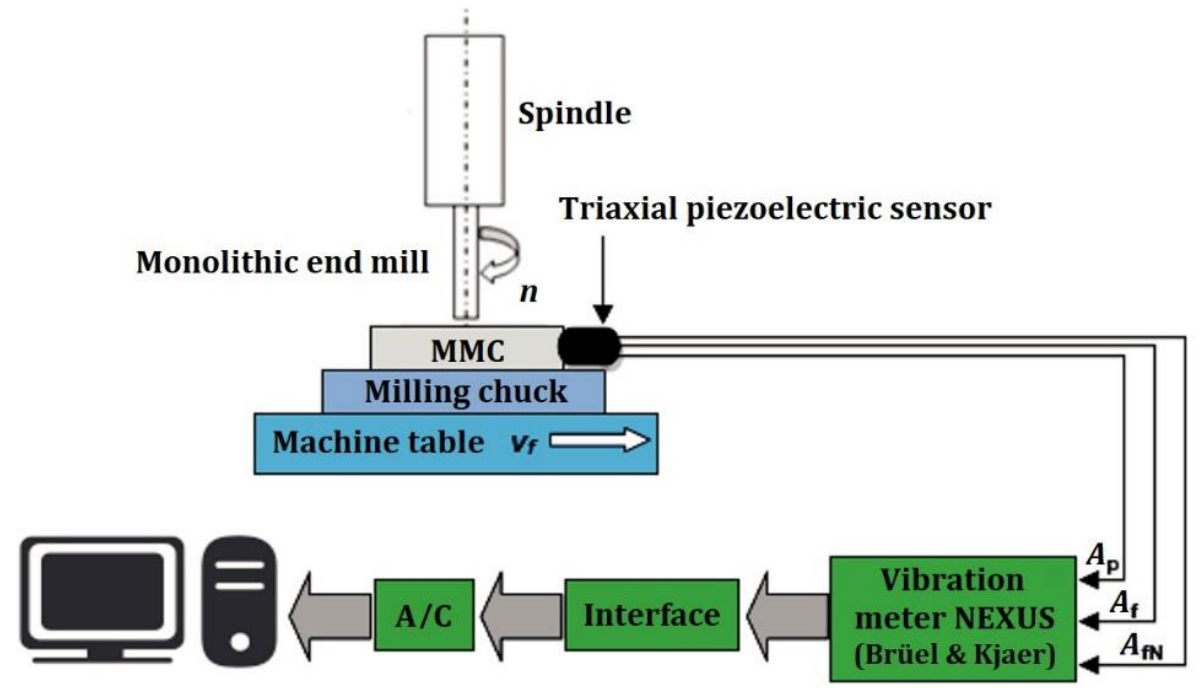

Fig. 1. Diagram of the measuring circuit

After a certain number of passes, the cutting edge wear width on the flank was measured (tool wear indicator $V B_{\mathrm{B}}$ ). The value of the tool life criterion $V B_{\mathrm{B}}=0.3 \mathrm{~mm}$ was adopted. Figure 2 shows an example of measuring the wear width on the flank of one of the tools used. The criterion value in this case was significantly exceeded: $V B_{\mathrm{B}}>0.3$.

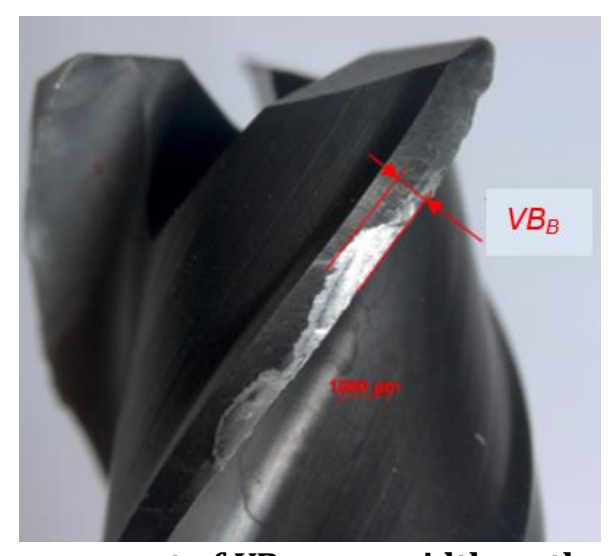

Fig. 2. Measurement of $V B_{B}$ wear width on the flank face 


\section{Tool wear analysis}

Based on the data from the $V B_{\mathrm{B}}$ wear width measurements, the tool wear is presented as a function of the milling time $t_{\mathrm{s}}$ for the cutters used (fig. 3).

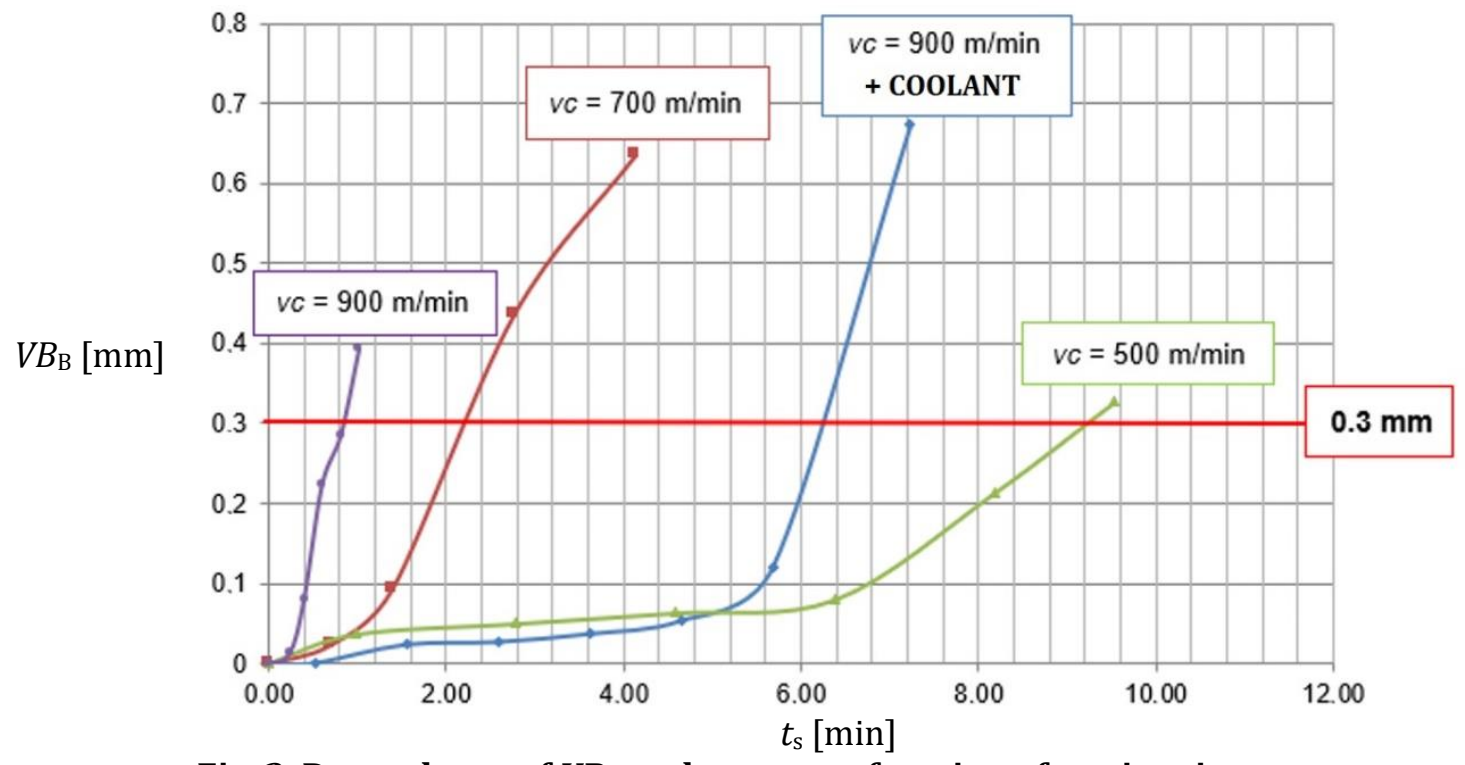

Fig. 3. Dependence of $V B_{\mathrm{B}}$ tool wear as a function of cutting time $t_{\mathrm{s}}$

One additional test with cooling lubricant was carried out for the maximum selected cutting speed $v_{\mathrm{c}}=900 \mathrm{~m} / \mathrm{min}$ to compare tool life. Figure 4 shows a comparison of the obtained tool life at different cutting speeds, calculated for the catastrophic failure $V B_{\mathrm{B}}=0.3 \mathrm{~mm}$.

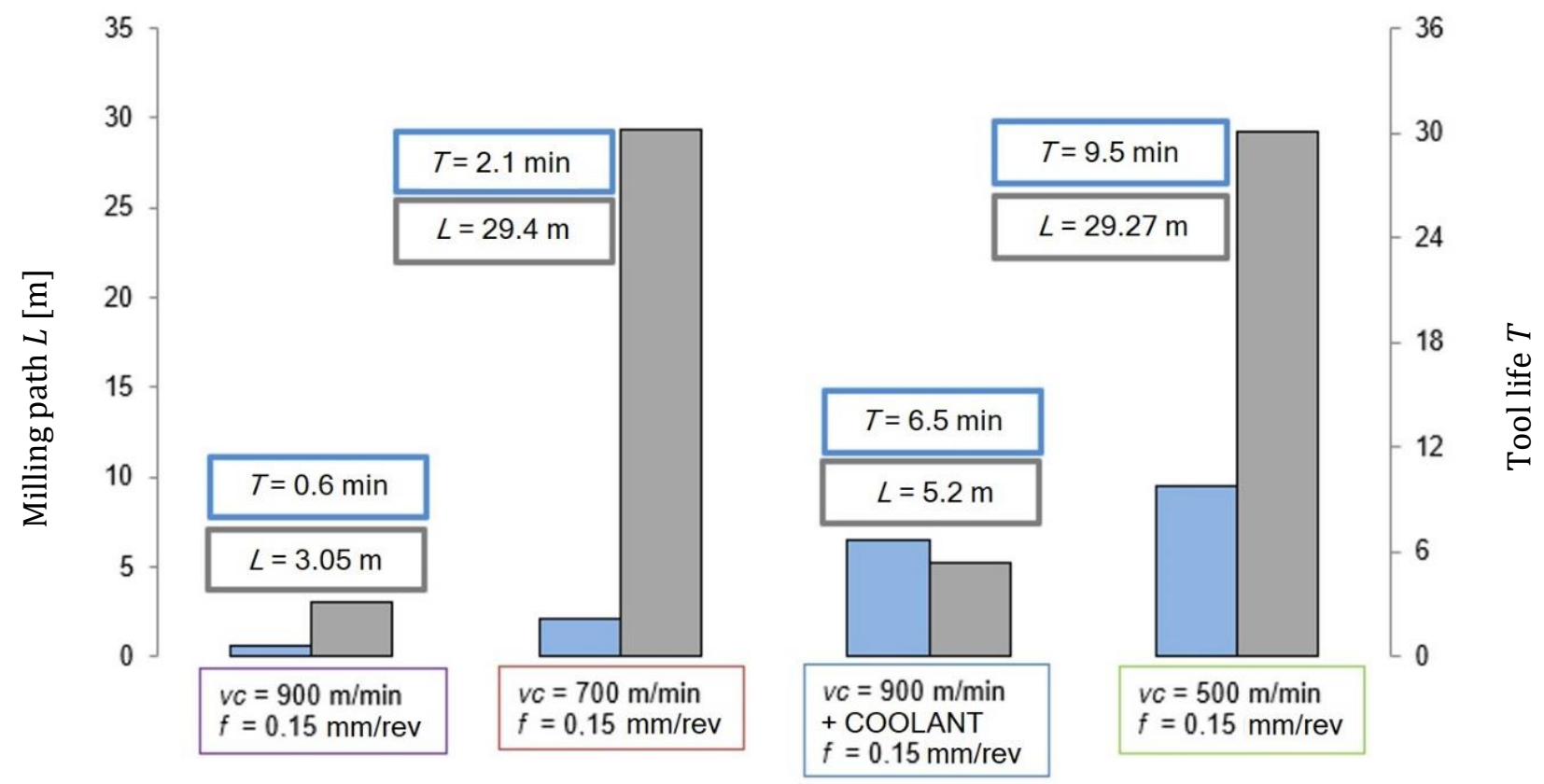

Fig. 4. Summary of $T$ tool life for each tool with a limit wear criterion of $0.3 \mathrm{~mm}$

\section{Analysis of vibration in the frequency domain}

Vibration analysis as a function of frequency is often used to diagnose the cutting tool wear. This analysis consisted in presenting the value of mechanical vibration acceleration as a function of frequency.

Due to the "Analyzer" software, it was possible to generate vibration waveforms and to read the acceleration values of these vibrations for characteristic frequencies of a given process. 
First, the frequency depending on the rotational speed was calculated:

$$
f_{01}=\frac{n_{1}}{60}=\frac{28648}{60}=477,5 \mathrm{~Hz}
$$

where: $n_{1}$ - rotational speed of the spindle used in the tests $[\mathrm{rpm}]$ for speed $v_{\mathrm{c}}=900 \mathrm{~m} / \mathrm{min}$.

To determine the next frequency characteristic for the process, the number of cutting edges of tools $z=3$ was taken into account and the frequency sought in the spectrum $f_{1}$ and the second harmonic $2 f_{1}$ were calculated:

$$
\begin{aligned}
& f_{1}=z \cdot f_{01}=3 \cdot 477,5 \approx 1433 \mathrm{~Hz} \\
& 2 f_{1}=2 \cdot f_{1}=2 \cdot 1433=866 \mathrm{~Hz}
\end{aligned}
$$

where: $z$ - number of cutting edges.

Fig. 5 shows relationship between the $V B_{\mathrm{B}}$ flank wear and value of vibration acceleration in all three considered directions. The relationship $V B_{\mathrm{B}}=a \cdot e^{b \cdot A_{i}}$ was developed and presented as a power function, while the $R^{2}$ factor determines the result's compliance with the adopted assumptions.

The figure summarizes the data obtained from tests carried out for three cutting speeds. The visible large dispersion of results can be explained by uneven distribution of ceramic particles in the MMC material, which can have a large impact on the appearance of random values of vibration accelerations during milling.

a)

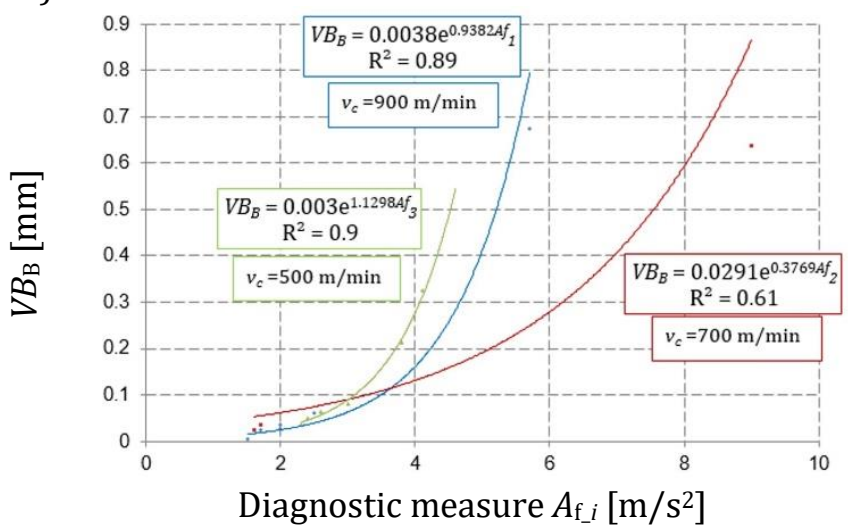

c)

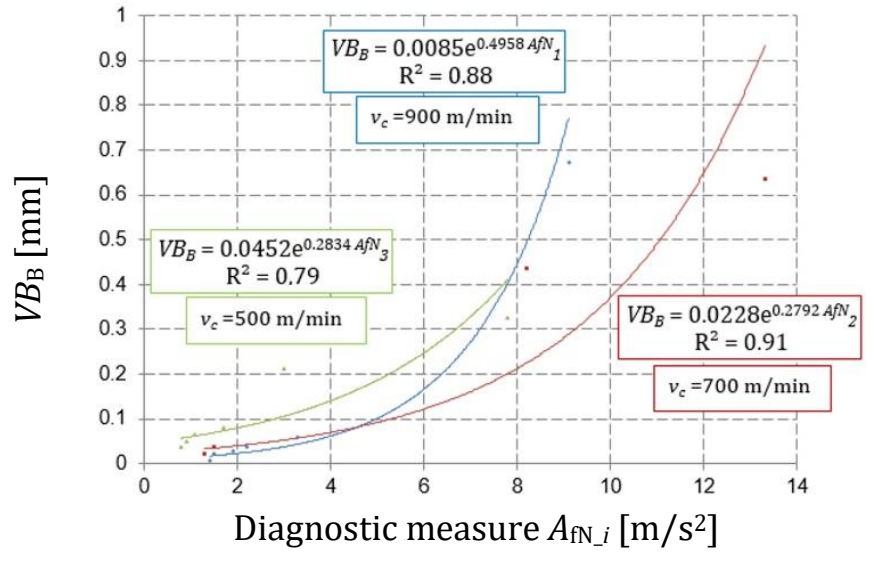

b)

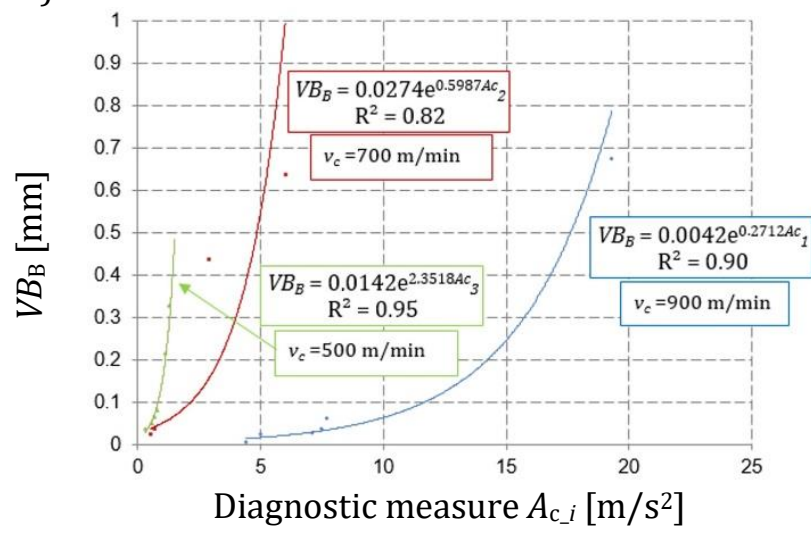

Fig. 5. Summary of $V B_{B}$ tool wear as a function of diagnostic measures at various cutting speeds: a) for measure $A_{\mathrm{f}_{-},}$, b) for measure $A_{\mathrm{c}_{-} i}$ and c) for measure $A_{\mathrm{fN}_{-} i}$

\section{Summary and conclusions}

Based on the research, the following conclusions can be made.

Analyzing the durability of the cutting edge of individual tools used at different cutting speeds, it can be stated that at the cutting speed $v_{\mathrm{c}}=500 \mathrm{~m} / \mathrm{min}$, the best tool life was obtained - about 4.5 times higher than at 
the speed of $v_{\mathrm{c}}=700 \mathrm{~m} / \mathrm{min}$. The lowest durability was obtained when milling at the maximum cutting speed $v_{\mathrm{c}}=900 \mathrm{~m} / \mathrm{min}$, thus from the point of view of a tool wear, the use of this cutting speed without coolant does not give satisfactory results. Due to the use of cooling at this speed, approximately 10 times longer tool life was achieved.

Analysis of vibration waveforms in the frequency domain has allowed for determination of the measurement direction that gives the most favourable effect in terms of monitoring. The best results and the most-favourable correlation coefficients were obtained when analysing $A_{\mathrm{c}}$ and $A_{\mathrm{fN}}$ measures. It can be concluded that in these directions, the power function has the largest fit, and hence - the information on tool wear is the closest to real.

To sum up the obtained results, monitoring of milling of difficult-to-cut materials, such as MMCs composites, brings satisfactory results based on mechanical vibrations. The problem may be the appearance of uneven distribution of ceramic particles in the workpiece, which leads to increased tool wear and unexpected sudden chipping of the cutting edge. The use of measurements of mechanical vibrations acceleration allows to correlate them with the tool wear.

\section{REFERENCES}

[1] Arun Premnath A., Alwarsamy T., Rajmohan T. "Experimental investigation and optimization of process parameters in milling of hybrid metal matrix composites". Materials and Manufacturing Processes. 27, 10 (2012): 1035-1044.

[2] Gururaja S., Ramulu M., Pedersen W. "Machining of MMCs: a review". Machining Science and Technology. 17, 1 (2013): 41-73.

[3] Han J., Hao X., Li L., Wu Q., He N. "Milling of high volume fraction SiCp/Al composite using PCD tools with different structures of tool edges and grain sizes". Int. Journal Adv. Manuf. Technol. 92 (2017): 1875-1882.

[4] Wiciak M., Twardowski P., Wojciechowski S. "Comparison of various tool wear prediction methods during end milling of Metal Matrix Composite". Archives of Mechanical Technology and Materials. 38, 1 (2018): 1-7.

[5] Przestacki D., Chwalczuk T. „Materiały narzędziowe stosowane podczas skrawania kompozytów metalowo-ceramicznych". Mechanik. 8-9 (2013): 339-344.

[6] Tomadi S.H., Ghani J.A., Mas Ayu H., Daud R. " Tool wear of uncoated carbide and PVD TiAlN coated carbide tools in end milling of AlSi/AIN metal matrix composite". Int. Journal of Advanced and Applied Sciences. 4, 9 (2017): 150-155.

[7] Ubeyli M., Acir A., Serdar Karakas M., Ogel B. " Effect of feed rate on tool wear in milling of Al4\%Cu/B4Cp Composite". Materials and Manufacturing Processes. 23, 8 (2008): 866-870.

[8] Kieruj P., Przestacki D., Chwalczuk T. „Analiza drgań podczas toczenia węglików spiekanych napawanych laserowo". Mechanik. 8-9 (2016): 1116-1117.

[9] Felusiak A., Twardowski P. "Diagnosis of edge condition based on force measurement during milling of composites". Archives of Mechanical Technology and Materials. 38, 1 (2018): 8-14.

[10] Caggiano A. "Tool Wear Prediction in Ti-6Al-4V Machining through Multiple Sensor Monitoring and PCA Features Pattern Recognition". Sensors MDPI. 18, 3 (2018): 823-1-14. 